\title{
Two papers on carbamazepine-induced hypersensitivity and its relationship to HLA status
}

\author{
A Anstey \\ Consultant Dermatologist, Aneurin Bevan Health Board, Wales, UK and Honorary Professor, Cardiff University, Wales, UK
}

TITLE Carbamazepine-induced toxic effects and HLA-B*I502 screening in Taiwan

Correspondence to A Anstey,

AUTHORS Chen P, Lin JJ, Lu CS et al.

Royal Gwent Hospital,

Cardiff Road, Newport,

Gwent, NP4 OTY

JOURNAL N Engl J Med 20I I; 364:I I26-33. doi:I0.1056/NEJMoa I0097I7

tel. $+44(0) 1633234450$

TITLE HLA-A*3I0I and carbamazepine-induced hypersensitivity reactions in e-mail alex.anstey@wales.nhs.uk

Europeans

AUTHORS McCormack M, Alfirevic A, Bourgeois S et al.

JOURNAL N Eng J Med 20I I;364:I I34-43. doi:10.1056/NEJMoa I0I 3297

DECLARATION OF INTERESTS No conflict of interests declared.

\section{SUMMARY}

In 1995 a report in the New England Journal of Medicine on medication use and risk of Stevens-Johnson syndrome/ toxic epidermal necrolysis (SJS/TEN) identified carbamazepine as a drug with a higher excess risk than most other drugs known to be associated with this severe muco-cutaneous drug reaction. ${ }^{3}$ Since then, pharmacogenomics (the study of the role of inherited and acquired genetic variation in drug response) has emerged as a new discipline, which is increasingly impacting on routine clinical practice. ${ }^{4}$ Perhaps the best known example of pharmacogenomics is variable thiopurine methyl transferase (TPMT) activity and the effect it has on azathioprine metabolism. Indeed, it is now the norm in the UK to measure TPMT activity before prescribing azathioprine in order to detect patients at risk of toxicity from conventional doses of this widely used drug. More recently, clinically relevant pharmocogenomic features have been identified for warfarin $^{5}$ and clopidogrel. ${ }^{6}$

These two papers from the 24 March 2011 issue of the New England Journal of Medicine concern the same topic: pharmacogenomics of human leukocyte antigen (HLA)related susceptibility to hypersensitivity reactions to carbamazepine. Two teams of researchers have used genome-wide association studies to identify HLA alleles that predict susceptibility to carbamazepine-induced SJS/ TEN. In Taiwan, previous research established HLAB*I502 as an important susceptibility marker for carbamazepine-induced Stevens Johnson syndrome. ${ }^{7}$ This led to a prospective study aimed at assessing HLAB*I502 prior to carbamazepine prescribing. The result was a dramatic reduction in SJS and TEN, preventing an estimated 10 cases of this potentially life-threatening complication of carbamazepine. The second study concerns HLA-typing to identify potential susceptibility markers for carbamazepine-induced SJS/TEN in European populations. McCormack et al reported HLA-A*3IOI as a susceptibility marker for carbamazepine-induced hypersensitivity reactions in subjects of Northern European ancestry.

\section{OPINION}

These two studies are important because they represent the most important component of biomedical research: the translation of research into patient benefit. In a relatively short period of time the Taiwanese group have made the leap from careful study of a serious clinical problem to the introduction of a simple test which they have proved can save lives. Their research started by focusing on a clinical problem that was more common in their local population than elsewhere in the world. They subsequently identified HLA-B*I502 to be strongly associated with risk of developing SJS induced by carbamazepine. They then applied this knowledge to the local population, saving an estimated 10 cases of this severe complication of carbamazepine therapy.

McCormack et al are on a similar journey: the identification of HLA-A*3IOI as a susceptibility marker for carbamazepine-induced hypersensitivity reactions in Europeans raises the prospect of using this knowledge prospectively, as in Taiwan, to reduce the risk of this lifethreatening drug reaction in this population.

How should this research be used to improve patient safety? Among persons of Han Chinese descent, 
carbamazepine-induced SJS/TEN almost never occurs in non-carriers of the HLA-B*I502 allele.' Thus, genotyping to prevent carbamazepine-induced SJS/TEN in routine practice seems to be warranted. All doctors who prescribe carbamazepine should consider testing for HLA-B*1502 when prescribing this drug in patients of Han Chinese descent. It is currently too soon to make a similar recommendation for pre-carbamazepine testing for HLA-A*3I0I in Europeans, as clinical research study to confirm the merit of such an approach has yet to be done. However, doctors who prescribe carbamazepine for large numbers of patients may wish to discuss such testing with their European patients (and with their colleagues in the relevant service laboratory). Additionally, all prescribers should be made aware of the pharmacogenomic implications of this research by appropriate alerts in the British National Formulary, Monthly Index of Medical Specialties (MIMS) and the carbamazepine drug data sheet.

\section{REFERENCES}

I Chen P, Lin JJ, Lu CS et al. Carbamazepine-induced toxic effects and HLA-B*I 502 screening in Taiwan. N Engl J Med 201 I; 364:I I 26-33. doi:I0.I056/NEJMoal0097I7

2 McCormack M, Alfirevic A, Bourgeois $S$ et al. HLA-A*3I0I and carbamazepine-induced hypersensitivity reactions in Europeans. $N$ Engl J Med 20 I I; 364: I I 34-43. doi: I0. I056/NEJMoa I0I 3297

3 Roujeau JC, Kelly JP, Naldi L et al. Medication use and the risk of Stevens-Johnson syndrome or toxic epidermal necrolysis. $N$ Eng J Med 1995; 333:I600-7. doi:I0.I056/NEJMI995I2I43332404

4 Wang L, McLeod HL, Weinshilboum RM. Genomic medicine: genomics and drug response. N Engl J Med 20 I I; 364: I | 44-53. doi 10.1056/NEJMra I0I0600

5 International Warfarin Pharmacogenetics Consortium, Klein TE, Altman RB et al. Estimation of the warfarin dose with clinical and pharmacogenetic data. N Engl J Med 2009;360:753-64.doi: I0.1056/ NEJMoa0809329. Erratum in N Eng J Med 2009; $361: 1613$.

6 Paré G, Mehta SR, Yusuf S, et al. Effects of CYP2CI 9 genotype on outcomes of clopidogrel treatment. N Eng J Med 2010; 363:I70414. doi: I0.1056/NEJMoa I0084I0

7 Chung WH, Hung Sl, Hong HS et al. Medical genetics: a marker for Stevens-Johnson syndrome.Nature 2004; 428:486. doi:I0.1038/428486a

\section{UPCOMING SYMPOSIA}

Dermatology

Paediatrics (RCPE/RCPCH joint symposium)

Diabetes

Renal Medicine

Trainees \& Members' Committee symposium

Preston symposium

Neurology (RCPE/RCGP joint symposium)

Cardiology

5 Ist St Andrew's Day Festival Symposium:

Update on Acute Medicine

21 September

29 September

7 October

13 October

28 October

9 November

16 November

25 November

I-2 December

\section{Book online at http://events.rcpe.ac.uk}

All symposia are held at the Royal College of Physicians of Edinburgh unless otherwise stated. Further symposia may be added at a later date.

\section{Programme details at:} http://events.rcpe.ac.uk or contact the Symposium Co-ordinator: Tel: 0I3I 2257324 Email: e.strawn@rcpe.ac.uk

\section{Webstreamed lectures}

If you are unable to attend symposia at the College in Edinburgh, selected lectures from all symposia are available to view and listen to in the Online Education section of the secure area of the College website. There are currently more than 100 lectures covering all the medical specialties and a range of generic topics. 